Journal of Humanities and Social Sciences Studies (JHSSS)

ISSN: 2663-7197

DOI: $10.32996 /$ jhsss

Journal homepage: https://al-kindipublisher.com/index.php/jhsss

\title{
Prevalence of Use of Social Network Sites among Adolescent Secondary School Students, Lilongwe, Malawi
}

John Kuyokwa*1 and Howard Bowa²

${ }^{1}$ Malawi College of Health Sciences, Private bag 396, Blantyre, Malawi; University of Malawi, Chancellor College, School of

Education, Zomba, Malawi

${ }^{2}$ Blantyre International University, Private Bag 98, Blantyre, Malawi

Corresponding Author: John Kuyokwa, E-mail: johnkuyokwa@gmail.com

\section{ARTICLE INFORMATION}

Received: October 08, 2020

Accepted: November 12, 2020

Volume: 2

Issue: 6

DOI: 10.32996/jhsss.2020.2.6.6

KEYWORDS

Prevalence, social network sites, adolescents, secondary school, Malawi

\section{ABSTRACT}

The purpose of this study was to determine the prevalence of use of social network sites among adolescent students in secondary schools. A cross-sectional study design was done and simple random sampling technique was used. Quantitative research methodologies were used in data generation and analysis. Data was collected in April (2019), $n=59$ students were involved. SPSSv26 and Excel were used in quantitative data analysis. $\mathrm{N}=59$ participants involved; Females (54\%) and Males (46\%). Aged between 10-19 years; attending year 1 to 4 of secondary school education. Gadgets used for social networking were smartphones (88\%), personal computers (8\%) and iPads (4\%). The social network sites that were used were Facebook, YouTube, LinkedIn, Twitter and WhatsApp. The study further observed that some students are bullied on social media platforms. The purpose for use of these social network sites was for the following reasons; entertainment (45\%), keep in contact with old friends (39\%), make new friends (10\%) and academic purposes (9\%). Adolescents are using social network sites in secondary schools. If the use of social media platforms can be well utilized, it may result in improved education among learners in low income settings like Malawi.

\section{Introduction}

The use of social network sites can help to improve adolescent learner's academic performance in Sub Saharan Africa and Malawi in particular. Learners can benefit from different social network platforms like WhatsApp, Facebook, YouTube, Linkedln and Twitter in terms of their education and social connectedness (Allen, Ryan, Gray, Mclnerney, \& Waters, 2014; Gray, Annabell, \& Kennedy, 2010). The use of social of network sites has been observed among adolescent learners in secondary schools across the world. The commonly used social network sites among adolescents are WhatsApp, Facebook, YouTube, LinkedIn and Twitter (Reich, Subrahmanyam, \& Espinoza, 2012; Wang et al., 2011). These social network sites help adolescents to share knowledge, have fun, on-line games, chatting and learn what others are doing(Hamm et al., 2015; Li, Barnett, Goodman, Wasserman, \& Kemper, 2013; Wang et al., 2011). However, in Malawi little has been done to find out the prevalence of use of social network sites among adolescent secondary school students. It is against this background that this study intended to explore the use of social network sites among adolescents in school. This study will add the body of knowledge to existing literature about use the social networks among adolescent learners in secondary schools.

\section{Literature Review}

The use of social network sites among adolescent secondary school students and its effects have been a topic of interest by various researchers over the years. This section reviews the literature published by different scholars on the topic of prevalence of use of social network sites among adolescent learners. For example a study by Bányai et al. (2017) on social media use among 5,961 adolescents based on European School Survey Project found that $89.45 \%$ of adolescents were using 
social network sites. Similar studies also reveal that everyone uses social network sites regardless of gender, age and year of study (Błachnio, Przepiórka, \& Pantic, 2015). In addition, a study in Nigeria by Ali (2015) among adolescent students found that many students who were using social networking platforms had used high amount of time on Facebook (88.9\%) compared to other social networks like Twitter (76.9\%), MySpace $(70.6 \%)$, and YouTube $(75.6 \%)$ and that they spent increasing amount of quality time on these social networks. In addition, a study by Tezci (2017) on use of social network sites found that the most commonly used social media among the students was Youtube and Facebook while MySpace and Linkedln came second. The study further observed that adolescents had different reasons of students' social media usage which included sharing documents, information and opinion, as well as entertainment. Social network sites also helps to have spontaneous interactions between students whereas the most common face-to-face interaction has transformed as technology has performed a critical supportive role for timely information sharing and coordinating visual meetings(Goodwin $K, 2010$ ). In addition, a study by Mukherjee et al. (2019) on cyber-bullying among 254 adolescents in higher secondary schools found that 22(10.5\%) students were cyberbullied and among those who were cyberbullied, majority (72.7\%) had no opinion and more than half (68.2\%) sought their friends' help. The next section will present the research methodology.

\section{Methodology}

This section presents the research design, the data collection methods, the study population, the sampling techniques, the data analysis procedures, the ethical considerations and the study limitations.

\subsection{Research design}

This study employed a cross-sectional study design while utilizing a quantitative approach in the processes of data collection and analysis. The researchers chose a quantitative research approach because of the nature of the study as it analyses the prevalence of use of social networks among adolescent students in secondary schools.

\subsection{Study area}

The study was conducted at a secondary school in Lilongwe Urban. Lilongwe district is a capital city of Malawi.

\subsection{Study population and sample size}

A total student population was 950 and students were in classes of from 1 to 4 of their secondary school education. The total population of 950 students was targeted at the school and 59 students were randomly sampled and participated in the study.

\subsection{Sampling techniques}

Simple random sampling technique was used because it gives the elements of the population equal opportunity of being part of the sample. Bacon-Shone (2015) posited that, random sampling technique is a probability sampling method in which all participants have equal chance of being selected. A simple random sample means that all sampling units in a particular population have an equal chance of selection(Bacon-Shone, 2015). Number of students from each class was obtained from the school headmaster and participants were randomly sampled from each class. The number of participants was as follows from each class; Form 1(15), Form 2(15), Form 3(10) and Form 4(19).

\subsection{Data collection}

The data collection instrument that was used in this research was the questionnaire which had series of open-ended questions and Likert scale.

\subsection{Data Analysis}

Data was analyzed using SPSS (Statistical Package for Social Sciences)-version 26 and descriptive data was presented inform of graphs like pie charts and histograms.

\subsection{Ethical Considerations}

A number of ethical guidelines were followed in this study. Firstly, school authorities and all participants consented before data were collected. Before the study all participating respondents were briefed about the study. The rights of participants were observed throughout the study. Participants were allowed to leave the study at any point in time they chose to do so and no harm was caused to the participants throughout this study. Privacy and confidentiality of data collected was ensured by the researchers at all times, no names of participants were recorded and data was stored in a secured place.

\subsection{Research Limitations/Delimitations}

The research had some limitations like the study was only done at only one secondary school in Lilongwe urban which may difficult to generalize to other schools in Lilongwe rural and the sample is was 59 which is not large enough to generalize for 
the whole adolescent population in Lilongwe district and Malawi as country. However, despite these limitations the study has strength because it has added knowledge of the prevalence of use of social networks among adolescent learners in Malawian secondary schools. Furthermore, the relevant authorities have knowledge that adolescent learners are using different platforms of social media which can be used to improve their education.

\section{Results and Discussion}

This section presents the results and discussions of the study findings. The purpose of this study was to investigate the prevalence of use of social network sites among adolescent students in Malawian secondary schools. The following areas have been discussed; participant demographics, device used for social networking, purpose for using social network sites, duration of social network sites and cyber bullying among adolescent learners.

\section{Demographic data}

They were 59 participants of which 32 (54\%) were females and 27(46\%) were males. The pie-chart (Figure 1) below shows the details.

\section{Gender of participants}

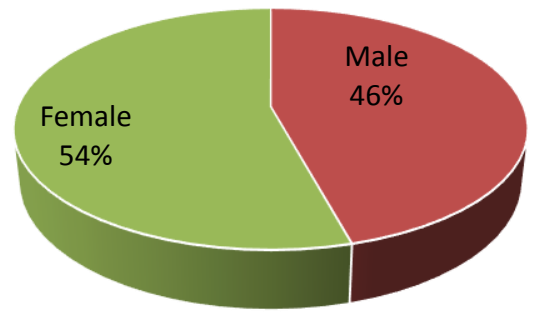

- Male

- Female

Figure 1 Gender of participants

The pie chart shows that $54 \%$ of participants were females and $46 \%$ of the participants were males. This shows that a majority of student participants were females.

\section{Age of the participants}

The study found that the participants were aged between 10 to 19 years. This age range is similar to what was observed by Kuyokwa etal. (2019) in their study in Blantyre, Malawi on epidemiology of psychoactive substance use among adolescent secondary schools. The Bar chart (Figure 2) shows the details.

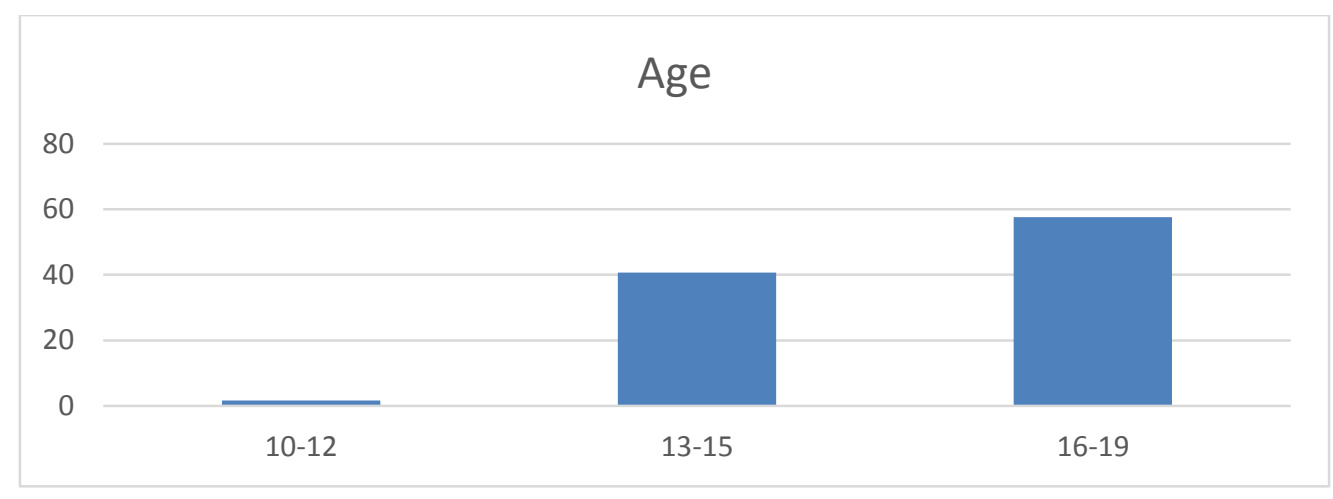

\section{Figure 2, Age of participants}

The results of figure 2 demonstrate that most of the participants (57.6\%) were aged between $16-19$ years while $40.7 \%$ were aged between $13-15$ years and only $1.7 \%$ was aged between $10-12$ years. 


\section{Smartphone ownership}

Study observed that $50 \%$ of the respondents had smart phones that they were using for social networks. This is similar to a study in Japan among adolescent learners in high school by Kamibeppu and Sugiura (2005) found that $49.3 \%$ of students were using smart phones. Figure 3 (Pie chart) below shows the details.

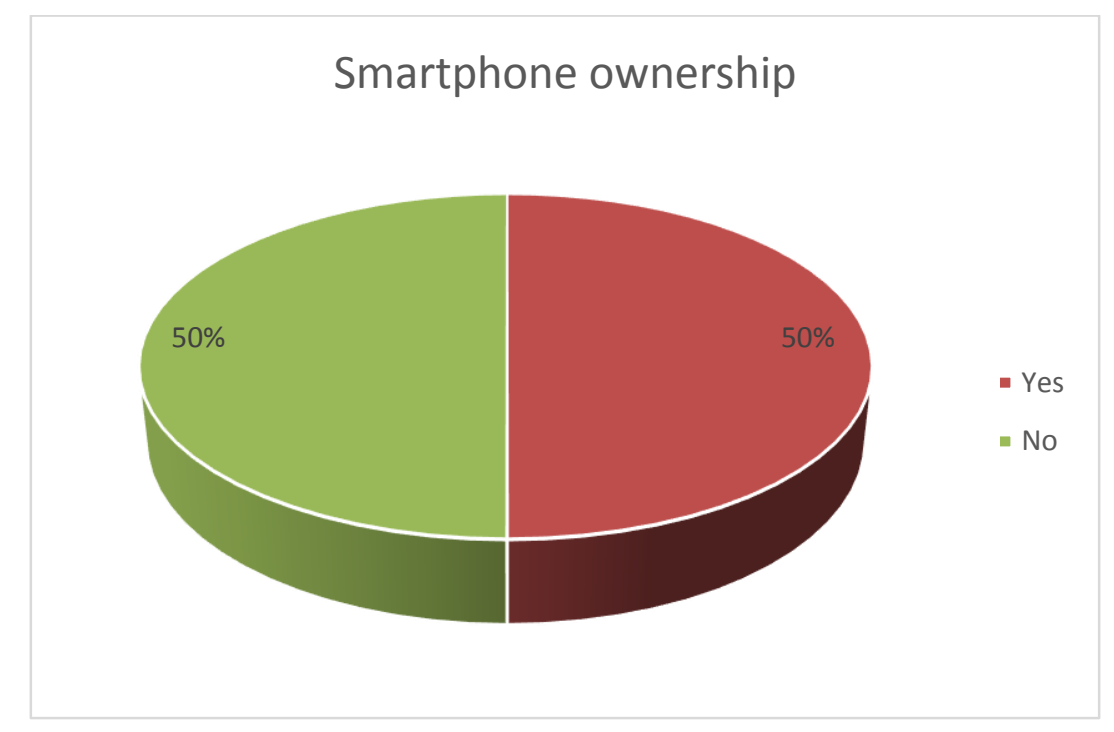

Figure 3, Smartphone ownership among participants

The figure 3 shows that $50 \%$ of the respondents own a smartphone while $50 \%$ do not own a smartphone. This shows that only half of the students have their own smartphone while the rest do not have a smartphone of their own.

\section{Devise used for social networking}

The study observed that learners use different types of gadgets when social networking. The Figure 4(Pie chart) below shows the details.

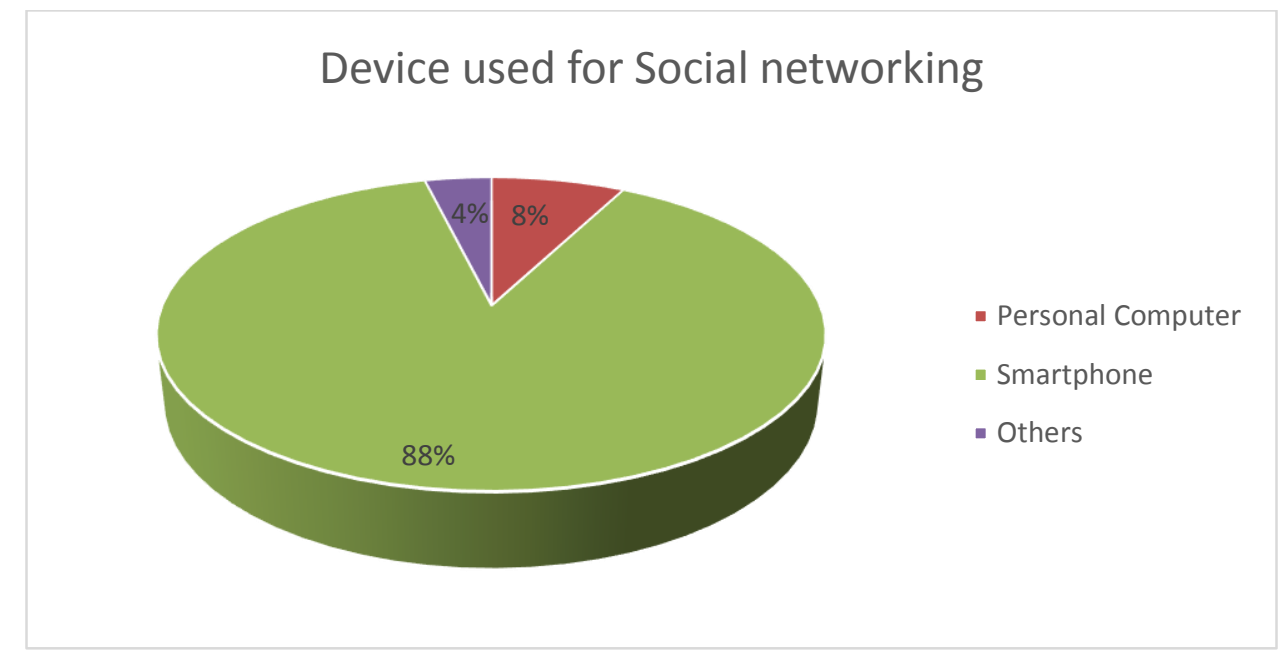

Figure 4, Device used for social networking by participants

The figure 4 shows that smartphones are the most used device for social networking among secondary school students as $88 \%$ of the students were found to be using smartphones, $8 \%$ were using personal computers and $4 \%$ use other devices like iPads. This may be due to the increased availability of the smartphone on the market as the most used device for communication in recent years in Malawi. The study further observed that despite not owning a smartphone of their own most students borrow from peers and family members who own smartphones. 


\section{Social network sites}

The study observed that adolescent learners were using the following social network sites; WhatsApp, Facebook, YouTube and LinkedIn. This is similar to what Greenhow and Askari (2017) observed in USA that students use different social network sites like Facebook, YouTube, MySpace and Linkedln for education purposes and social interaction.

\section{Purpose of social networking}

The study observed that adolescent students had different reasons why students were using social networks. The figure 5 (Pie chart) below shows the details

\section{Purpose for using Social Networking}

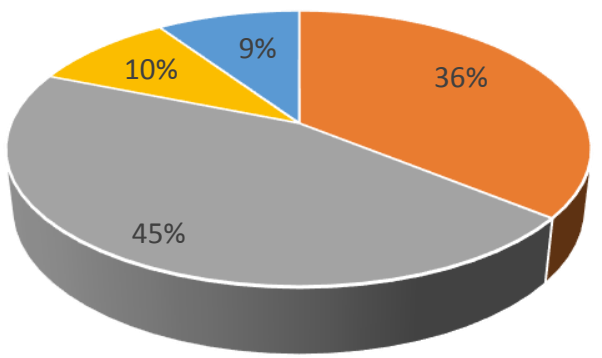

- Keeping in contact with old friends

- Entertainment

- Make new friends

- Academic

\section{Graph 5 - Purpose for which Students Use Social Networks}

The pie chart shows that students mainly use social networks for entertainment as majority (45\%) of respondents said they use social networks for entertainment, $39 \%$ use social networks to keep in contact with old friends, $10 \%$ use them to make new friends, and only 9\% use social networks for academic purposes. Similarly, Rosenfeld Halverson (2011) also asserts that social network sites can be used for education purposes among students.

\section{Duration of social networking}

The study found that adolescent learners who were using the social network sites had varied durations. Similarly, a study by (!!! INVALID CITATION !!! Nursalam, Octavia, Tristiana, and Efendi (2019)) in Indonesia found that duration of use of social network sites varied among adolescent students. Figure 6(Bar Chart) below shows the details.

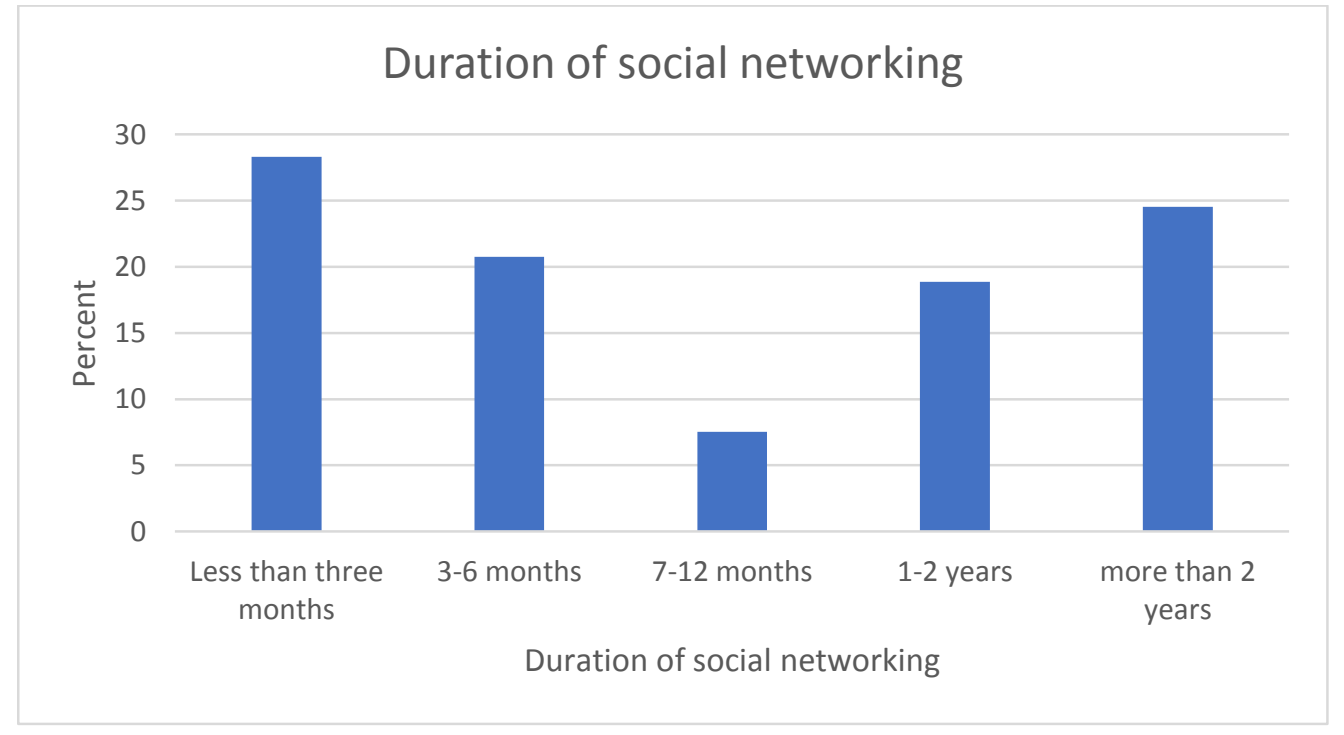

Figure 6 - Duration of social network use for students 
The figure 6 shows that majority (28.3\%) have been using social networks in less than three months, $20.8 \%$ for the duration of 3 to 6 months, $7.5 \%$ for 7 to 12 months, $18.9 \%$ for 1 to 2 years and $24.5 \%$ for more than 2 years. This indicates that a majority of the students were new to Social Networks however, another large number of students have been users of social networks for more than 2 years.

\section{Use of social networks per week}

The study observed that the use of network per week varied among study participants. Figure 7(Bar chart) below shows the details.

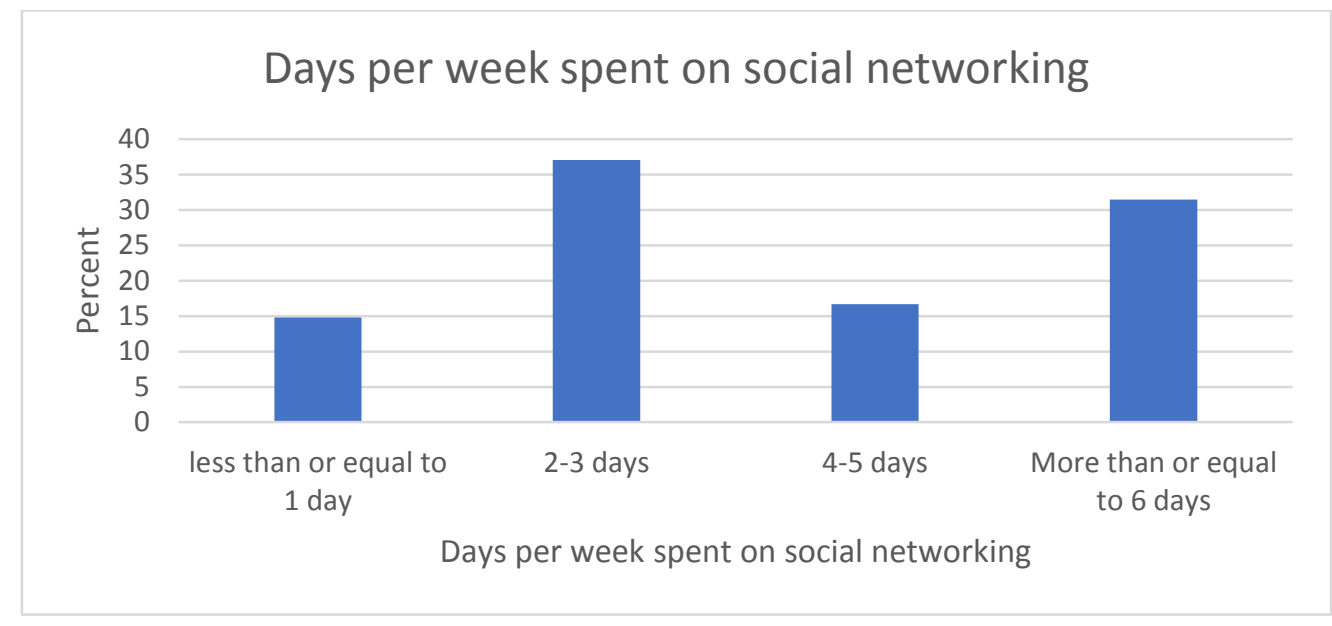

\section{Graph 7 - Days per week students spend on social networks}

The figure 7 shows that majority (37\%) use social networks for 2 to 3 days in a week, 31.5\% use social networks for a period of more than or equal to 6 days, $14.8 \%$ use social networks for a period of less than or equal to 1 day, $16.7 \%$ for 4 to 5 days per week. These results point that many students use social networks moderately during the week however, there is a small difference between students that use social networks moderately and those that use social networks heavily for more than or equal to 6 days per week.

\section{Amount of time per day spent of social networks}

The study found that the duration of student's use of social networks varied as well. Figure 8(Bar chart) below shows the details.

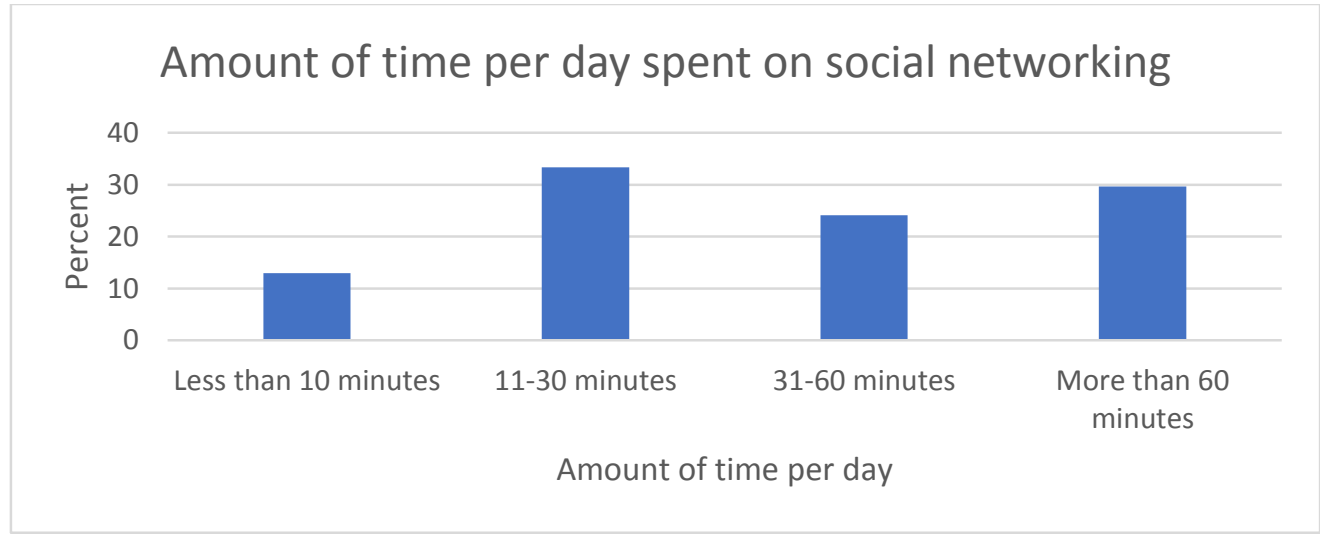

Figure 8, Amount of time per day spent of social networks

The figure show that $13 \%$ of students spend less than 10 minutes on social networks a day, $33.3 \%$ of students spend $11-30$ minutes on social networks per day, $24.1 \%$ of students spend $31-60$ minutes on social networks and $29.6 \%$ spend more than 60 minutes on social networks. This indicates that many students use social networks moderately during the day. However, there is no big difference between students that use social networks moderately and those that use social networks for more than 60 minutes per day. 


\section{Social Networking and Cyber-bullying}

The study observed that some adolescent learners were cyber bulled by different people. Figure 9(Bar chat shows the details)

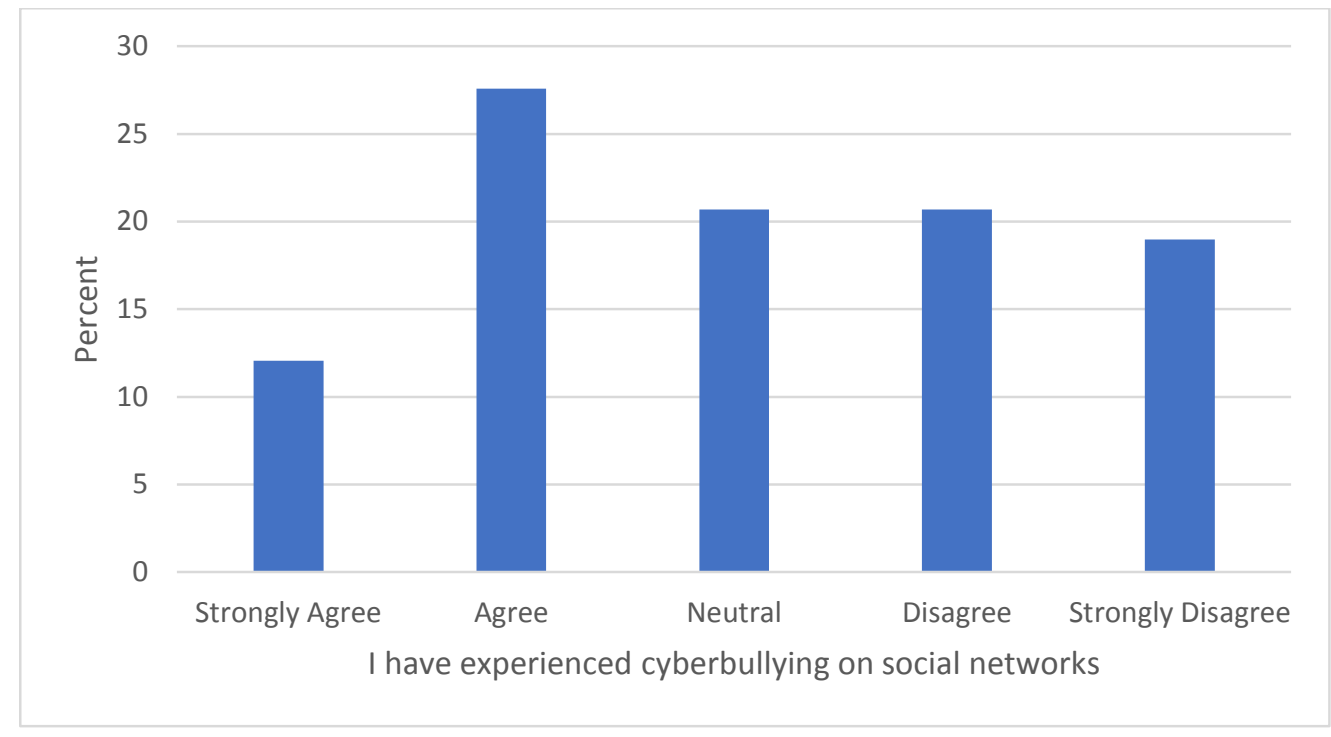

\section{Figure 9- Social Networking and Cyber-bullying}

The figure 9 , shows that $12.1 \%$ strongly agreed that they have experienced cyber-bullying on social networks, $27.6 \%$ agreed, $20.7 \%$ were neutral, $20.7 \%$ disagreed and $19 \%$ strongly disagreed. This shows that majority of students have experienced cyber-bullying. The type of cyber-bulling were bad comments on posts, hurtful comments, abusive comments on the appearance of their photos, insults and exposure to inappropriate materials such as nude images of women. Some female respondents reported being forced to send nude photos or be killed by strangers on social networks. However, some students reported that cyber-bullying is a normal part of social media. Although, a similar study by Mukherjee et al. (2019) on cyber-bullying among 254 adolescents in higher secondary schools found a lower percentage of 22(10.5\%) students were cyberbullied and among those who were cyberbullied, majority (72.7\%) had no opinion and more than half (68.2\%) sought their friends' help.

\section{Social Networking and feelings of Fear of Missing Out (FOMO)}

The study observed that some adolescents had feelings of fear of missing out of the social network sites. The figure 10(Bar chart) below shows the details.

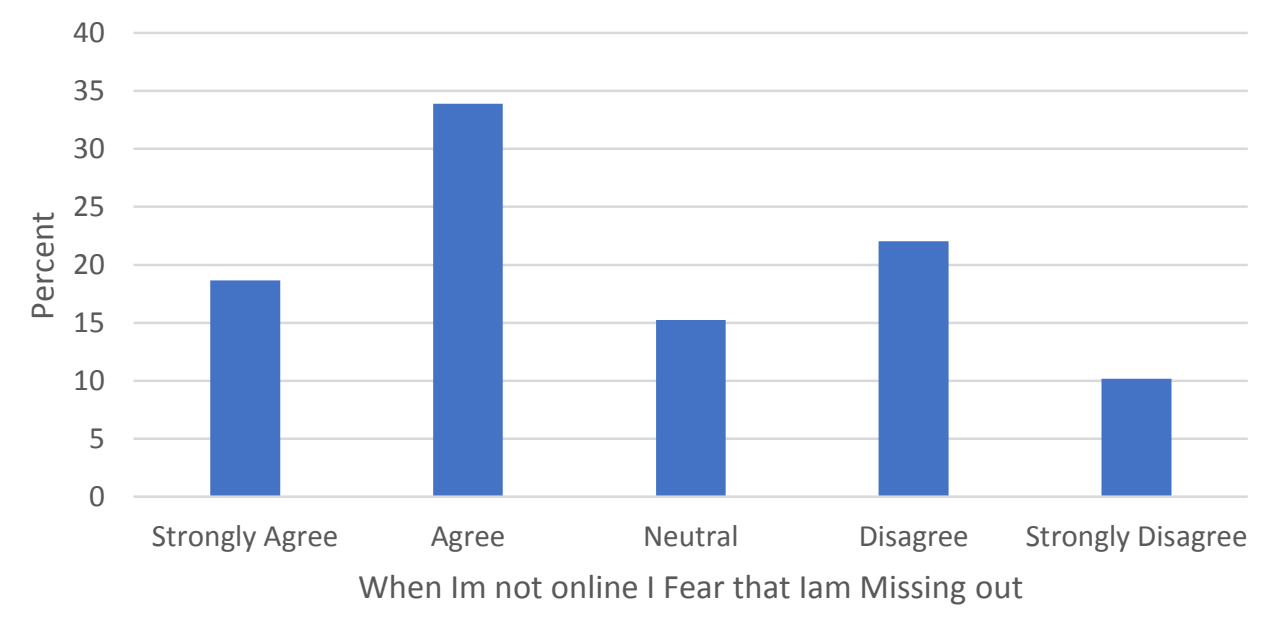

Figure 10, Social networking and Fear of Missing Out 
The figure 10 shows that $18.6 \%$ of the students strongly agreed to feel fear of missing out when offline, $33.9 \%$ agreed, $15.3 \%$ were neutral, $22 \%$ disagreed and $10 \%$ strongly disagreed. The results show a majority of students are afraid of missing out. Some of the students said they don't want to be left behind, most of the students are afraid of missing out on group discussions about school work. Some students reported that they don't want to miss sent and received friend requests to see whether they have been responded to. Roberts and David (2019) study also observed that students also had feelings of social networking and fear of missing out from friends.

\section{Social Networking and academic performance}

The study observed that some participants were affected academically due to use of the social network sites. The figure 11(Bar Chart) below shows the details.

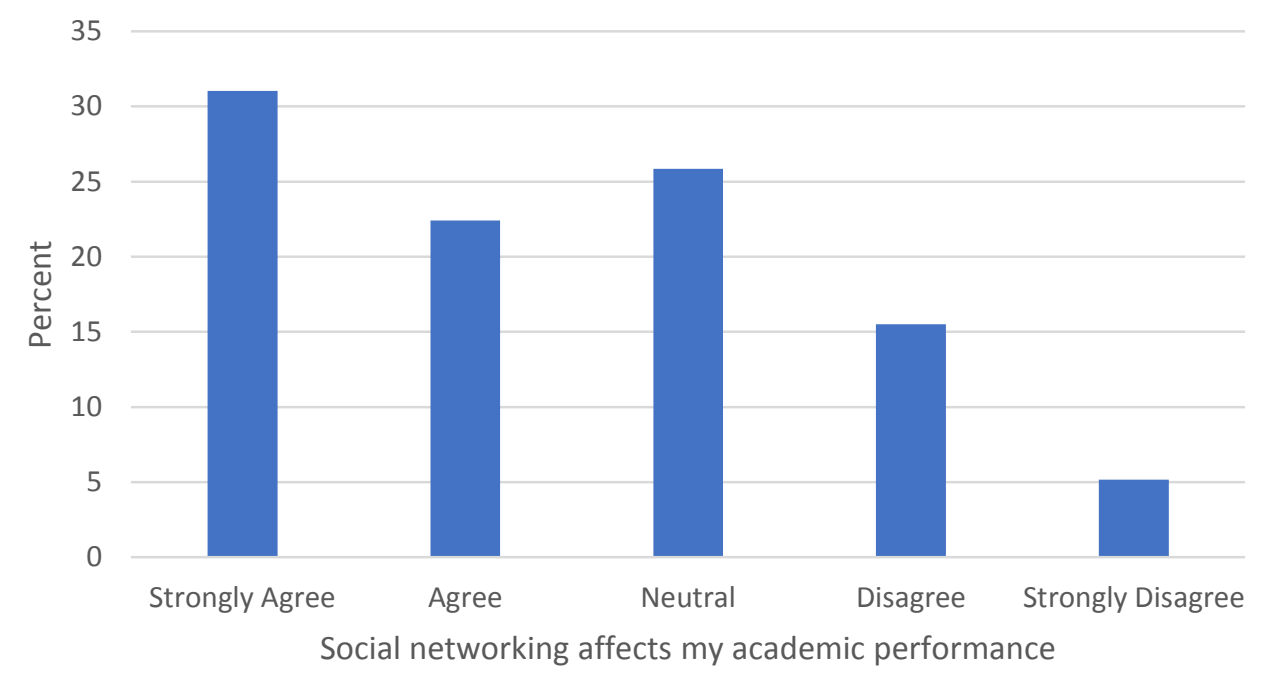

Figure 11, Social networking and academic performance

Figure 11 shows that $31 \%$ of the students strongly agreed, $22.4 \%$ agreed, $25.9 \%$ were neutral, $15.5 \%$ disagreed and $5.1 \%$ strongly disagreed. According to the results a majority of students strongly agreed that social networking affects their academic performance. The students reported that they spend more time chatting with friends on social networks instead of doing homework and studying. Some students also said social networks effect their concentration during class time because they think about whether someone has answered their friend request on Facebook. Students also reported that they spend money on credit to stay online instead of buying school materials and some students sleep late because of social networking. However, the students that disagreed said social networks help them access information about school. Similarly, a study by Azizi, Soroush, and Khatony (2019) found that social networking addiction had an impact on academic performance among Iranian students.

\section{Conclusion}

The objective of this study was to determine the prevalence of use of social network sites among adolescent students in secondary schools. The study found that students use social network sites in secondary schools in Malawi and about $50 \%$ of the study participants were using social media. However, the level of usage of social network site varies. The study further observes that use of social network sites affects students' academic performance and students feel missed out when they don't utilize the social media platforms. In addition, the study found that adolescent students are bullied on the social network platforms. Therefore, relevant authorities can take advantage of social media as a platform to disseminate relevant knowledge to adolescent learners and mange cyber bullying. Further research should be done on the impact on the use of social network sites on academic performance among adolescent learners. 


\section{References}

[1] Ali, F. A. F. A., Umar Yanda. (2015). The Use of Social Networking among Senior Secondary School Students in Abuja Municipal Area of Federal Capital Territory, Nigeria.pdf. Journal of Education and Practice, v6 n15 p15-22 2015, 6.

[2] Allen, K. A., Ryan, T., Gray, D. L., McInerney, D. M., \& Waters, L. (2014). Social Media Use and Social Connectedness in Adolescents: The Positives and the Potential Pitfalls. The Australian Educational and Developmental Psychologist, 31(1), 18-31. doi:10.1017/edp.2014.2

[3] Azizi, S. M., Soroush, A., \& Khatony, A. (2019). The relationship between social networking addiction and academic performance in Iranian students of medical sciences: a cross-sectional study. BMC Psychology, 7(1), 28. doi:10.1186/s40359-019-0305-0

[4] Bacon-Shone. (2015). Introduction to Quantitative Research Methods.pdf. Quantitative Research Methods course book.Book . February 2015. DOI: 10.13140/2.1.4466.3040. doi:10.13140/2.1.4466.3040

[5] Bányai, F., Zsila, Á., Király, O., Maraz, A., Elekes, Z., Griffiths, M. D., . . Demetrovics, Z. (2017). Problematic Social Media Use: Results from a Large-Scale Nationally Representative Adolescent Sample. PLoS One, 12(1), e0169839. doi:10.1371/journal.pone.0169839

[6] Błachnio, A., Przepiórka, A., \& Pantic, I. (2015). Internet use, Facebook intrusion, and depression: Results of a cross-sectional study. Eur Psychiatry, 30(6), 681-684. doi:10.1016/j.eurpsy.2015.04.002

[7] Goodwin K, K. G., Vetere F. ( 2010). Getting together out-of-class: Using technologies for informal interaction and learning.pdf.

[8] Gray, K., Annabell, L., \& Kennedy, G. (2010). Medical students' use of Facebook to support learning: insights from four case studies. Med Teach, 32(12), 971-976. doi:10.3109/0142159x.2010.497826

[9] Greenhow, C., \& Askari, E. (2017). Learning and teaching with social network sites: A decade of research in K-12 related education. Education and Information Technologies, 22(2), 623-645. doi:10.1007/s10639-015-9446-9

[10] Hamm, M. P., Newton, A. S., Chisholm, A., Shulhan, J., Milne, A., Sundar, P., . . . Hartling, L. (2015). Prevalence and Effect of Cyberbullying on Children and Young People: A Scoping Review of Social Media Studies. JAMA Pediatrics, $169(8), 770-777$. doi:10.1001/jamapediatrics.2015.0944

[11] Kamibeppu, K., \& Sugiura, H. (2005). Impact of the mobile phone on junior high-school students' friendships in the Tokyo metropolitan area. Cyberpsychol Behav, 8(2), 121-130. doi:10.1089/cpb.2005.8.121

[12] Kuyokwa etal. (2019). Epidemiology of Psychoactive Substance Use and Associated Factors among Adolescents: A Descriptive Study of Selected Secondary Schools in South West Education Division, Blantyre, Malawi.pdf. Journal of Global Health Vol.3 No.1:1., 3.

[13] Li, J. S., Barnett, T. A., Goodman, E., Wasserman, R. C., \& Kemper, A. R. (2013). Approaches to the prevention and management of childhood obesity: the role of social networks and the use of social media and related electronic technologies: a scientific statement from the American Heart Association. Circulation, 127(2), 260-267. doi:10.1161/CIR.0b013e3182756d8e

[14] Mukherjee, S., Sinha, D., De, A., Misra, R., Pal, A., \& Mondal, T. K. (2019). Cyberbullying among late adolescent: A cross-sectional study in two higher secondary schools of Kolkata, West Bengal. Indian J Public Health, 63(1), 86-88. doi:10.4103/ijph.IJPH_92_18

[15] Reich, S. M., Subrahmanyam, K., \& Espinoza, G. (2012). Friending, IMing, and hanging out face-to-face: overlap in adolescents' online and offline social networks. Dev Psychol, 48(2), 356-368. doi:10.1037/a0026980

[16] Roberts, J., \& David, M. (2019). The Social Media Party: Fear of Missing Out (FoMO), Social Media Intensity, Connection, and WellBeing. International Journal of Human-Computer Interaction, 1-7. doi:10.1080/10447318.2019.1646517

[17] Rosenfeld Halverson, E. (2011). Do social networking technologies have a place in formal learning environments? On the Horizon, 19(1), 62-67. doi:10.1108/10748121111107717

[18] Tezci, E. I., Mustafa. (2017). High School Students' Social Media Usage Habits.pdf. Online Submission, Journal of Education and Practice v8 n27 p99-108 2017, 8.

[19] Wang, H., Zhou, X., Lu, C., Wu, J., Deng, X., \& Hong, L. (2011). Problematic Internet Use in High School Students in Guangdong Province, China. PLoS One, 6(5), e19660. doi:10.1371/journal.pone.0019660 